\section{Kinetico-mechanistic study on the reduction/complexation sequence of PtIV/PtII organometallic complexes by thiol-containing biological molecules}

Margarita Crespo ${ }^{\mathrm{a}}$, Mercè Font-Bardia ${ }^{\mathrm{b}}$, Peyman Hamidizadeha, ${ }^{\mathrm{c}}$, Manuel Martínez ${ }^{\mathrm{a}}$, S. Masoud Nabavizadeh ${ }^{\mathrm{c}}$

a Departament de Química Inorgànica i Orgànica, Secció de Química Inorgànica, Universitat de Barcelona, Martí i Franquès 1-11, E-08028 Barcelona, Spain

b Unitat de Difracció de RX. Centres Científics i Tecnològics de la Universitat de Barcelona (CCiTUB), Solé i Sabarís 1-3, E-08028 Barcelona, Spain

c Department of Chemistry, College of Sciences, Shiraz University, Shiraz 71454, Iran

margarita.crespo@qi.ub.es (M. Crespo),

manel.martinez@qi.ub(M. Martínez). 
ABSTRACT:

42 The kinetics of the reaction of [PtIV(4X-Cph, $\left.\left.\mathrm{N}^{\mathrm{N}} \mathrm{N}^{\prime}\right) \mathrm{Cl}(\mathrm{Y}) 2\right]$ complexes $(2-\mathrm{X}-\mathrm{Y})(\mathrm{X}=\mathrm{Cl}$ or $\mathrm{F}$ and $\mathrm{Y}=\mathrm{OH}$

43 or $\mathrm{Cl}$ ) with biological thiols (glutathione, cysteine, thiolactic acid) and methionine, has been monitored

44 by UV-Vis spectrophotometry. The reactions have been followed at varying pHs and chloride

45 concentrations (within the physiological range) and different temperatures and pressures. The bis-

46 chlorido derivatives, $2-\mathrm{X}-\mathrm{Cl}$, have been found to react with cysteine, glutathione and thiolactic acid,

47 while the bis-hydroxido 2-X-OH derivatives are not reduced due to the high potential of the PtIV/PtII

48 pair, as measured in aqueous solution. The lack of reactivity of methionine is related with its tioether

49 nature preventing deprotonation of the $\mathrm{S}$ donor. In all remaining cases, two consecutive reaction steps

50 have been found to occur. For cysteine the two steps can be kinetically resolved, the first step being

51 neatly related to a PtIV to PtII reduction and the second step corresponding to the substitution of the

52 remaining $\mathrm{Cl}$ - ligand by cysteine. The nature of the second step has been also confirmed by ESI-MS, as

53 well as by the associative character of the activation parameters determined (low $\Delta \mathrm{H} \neq$ and very negative

$54 \Delta \mathrm{S} \neq$ and $\Delta \mathrm{V} \neq)$. For glutathione and thiolactic acid, the rate and thermal and pressure activation

55 parameters for the reduction step has been found similar to that obtained for the reaction with cysteine,

56 but the substitution step could not be resolved kinetically. The substitution step, as measured from the

57 reduced [PtII(4X-Cph, $\left.\left.\mathrm{N}^{\prime} \mathrm{N}^{\prime}\right) \mathrm{Cl}\right]$ complex, is faster than the reduction process, and also much faster than

58 that observed for the reaction with cysteine. In both cases the final product resulting for the reduction

59 reactions corresponds thus to the final substituted complex as found for the reaction with cysteine.

60 
63 Since the discovery of the anticancer effects of cisplatin (cis- [PtCl2(NH3)2]) by Rosenberg, the antitumor activity of certain PtIV compounds such as cis-[PtCl4(NH3)2] was also noticed [1-3]. In recent years, platinum complexes with non-classical structures such as PtIV compounds or with different mechanisms of action than cisplatin have been thoroughly investigated [4-5]. Nevertheless, despite the worldwide application of PtII complexes such as cisplatin, carboplatin and oxaliplatin, there is no PtIV complex approved for clinical use so far [6]. Given the inertness of PtIV compounds, it is generally accepted that the PtIV compounds may be reduced in vivo by molecules present in the cell, such as glutathione, L-cysteine, L-methionine or ascorbic acid, to PtII compounds which, in turn, could exert their cytotoxic activity. Properly designed PtIV complexes display several advantages since their inertness diminishes side effects and prevents deactivation before entering the cancer cell, and their higher lipophilicity renders them more suitable for oral administration. The prototype of PtIV anticancer agents involves, in addition to two non-leaving groups and two substitutionally active groups as for cisplatin analogues, the presence of two axial ligands which can dissociate after biological reduction. These ligands can be used to modulate the reduction parameters, kinetic stability, lipophilicity and pharmacological properties of the prodrug. Therefore, a versatile strategy is to combine clinically relevant PtII drugs with adequate axial ligands [2,6-12]. A common route to introduce these two additional axial ligands consists of a two-electron oxidation of a PtII precursor and the most widely used oxidizing agents are hydrogen peroxide and chlorine, which give trans addition products [3]. Since PtIV compounds act as prodrugs which are activated by reduction, the reduction potential is a key pharmacological parameter to predict the activity of these compounds. On one hand, very high redox potentials might lead to straightforward fast reduction and severe side effects, as those found for cisplatin, thus representing a serious drawback despite its original more benign design. On the other hand, a lack of anticancer activity might be related with too low reduction potentials which would keep the complex with rather inert characteristics, thus not allowing its interaction with the DNA molecule [7]. The reduction potentials are dependent on the nature of both axial and equatorial ligands, but in general the effect of the leaving axial ligands is more relevant. In particular, for a series of PtIV compounds with axial chlorido, acetato and hydroxido ligands, the ease of reduction follows the trend $\mathrm{Cl}$ $>\mathrm{OAc}>\mathrm{OH}[13,14]$. Hydroxido ligands possess strong electron donating properties and the resulting complexes are difficult to be reduced [15]. It was originally assumed that a correlation exists between the biological activity of the PtIV prodrugs, the reduction potentials and the rates of reduction. However, the reduction potentials have been found to not necessarily correlate with the rates of reduction of PtIV complexes [16,17]. In fact, the rates of reduction depend on the ability of the ligands in the coordination sphere of the PtIV species to associate with the reducing agent which facilitates the electron transfer [18]. Moreover, although the reduction of 
complexes [19], several studies indicate that reductants such as glutathione might coordinate to the resulting PtII species, thus resulting in an already substituted cisplatinum analogue that might, or might not, interact with the DNA molecules [20-22]. Therefore, in spite of the great deal of attention recently devoted to PtIV antitumor drugs, more studies aimed at disclosing the nature and substitutional reactivity of the produced PtII compounds are needed. By doing so, it should be possible to fully understand the precise mechanisms of the reduction process and thus develop a rational design of new compounds with better pharmacokinetic tuning properties which have been found to be the keystone for its activity.

On the other hand, recent studies indicate that organometallic compounds are promising anticancer agents in spite of the initial idea that these compounds would be unstable under physiological conditions. The presence of some strong $\mathrm{M}-\mathrm{C}$ bonds improves the stability of these compounds and greatly influences the lability of the other bonds present. In addition, organometallic compounds are easily modified and thus suitable for the establishment of structure-activity relationships [23-25]. In particular, cyclometallated compounds [26] are appealing since they are easily obtained for a wide range of different ligands and metals; furthermore, they can be rather stable versus hydrolysis in aqueous media and present a good tuning of the polarity needed for going across membranes. In this respect the careful choice of complexes with just one Pt-C bond is extremely relevant for the maintenance of the substitutional associative activation of the final PtII complex formed, thus enabling its reactive discrimination among the wealth of potential substituting ligands in the reaction medium. Following our interest in cyclometallated platinum compounds, we have recently shown that PtIV metallacycles present cytotoxic properties [27], and, on the other hand, they are adequate platforms for kinetico-mechanistic studies of oxidative addition and reductive elimination processes [28]. Therefore, cyclometallated PtIV compounds are excellent candidates to study their reactivity towards reductants such as glutathione and other biologically relevant thiols. Furthermore, the resulting PtII species can be independently prepared and its substitutional activity also monitored under the same conditions. Although several kinetico-mechanistic studies of reactions of PtIV compounds with this type of reductants have been reported [19,29-33], to the best of our knowledge this is the first one which involves cyclometallated compounds which can be easily tuned, both in the reduction potential and in the substitutionally reactivity aspects of the reduced PtII species obtained. The aim of this work is to use $\left[\mathrm{C}, \mathrm{N}, \mathrm{N}^{\prime}\right]$ cyclometallated compounds as models to establish the reactivity sequence of PtIV compounds with biologically relevant reductants in order to provide a deeper understanding of these processes so that more efficient PtIV prodrugs can be designed. 


\subsection{Compounds}

The syntheses of [C,N,N'] cyclometallated PtII compounds containing a chloro (1-Cl in Scheme 1) [34] or a fluoro (1-F in Scheme 1) [35] substituent have been previously reported. As for cisplatin, these cyclometallated PtII compounds contain two substitutionally active positions: the chlorido ligand and the dimethylamino moiety of the terdentate $\left[\mathrm{C}, \mathrm{N}, \mathrm{N}^{\prime}\right]$ ligand. This has been evidenced upon the reactions of 1-Cl with monodentate and bidentate phosphines which lead respectively to dissociation of the $\mathrm{NMe} 2$ moiety to produce a neutral compound, or to dissociation of both the $\mathrm{NMe} 2$ and the chlorido ligand to produce an ionic compound [34]. Oxidative addition of either $\mathrm{Cl} 2$ or $\mathrm{H} 2 \mathrm{O} 2$ on these compounds has been carried out in this work following reported procedures [36,37] and gave the desired cyclometallated PtIV compounds 2-Cl-Cl, 2-Cl-OH and 2-F-Cl depicted in Scheme 1.

The structure of compound 2-Cl-Cl was determined (CCDC deposition number 1828170) by single crystal XRD and is shown in Fig. 1. As expected from NMR studies, the platinum atom displays an octahedral coordination with a meridional tridentate $\left[\mathrm{C}, \mathrm{N}, \mathrm{N}^{\prime}\right]$ ligand. An equatorial and two axial chlorido ligands complete the coordination around the platinum, and the axial chlorido ligands form a $\mathrm{Cl}-\mathrm{Pt}-\mathrm{Cl}$ angle of $174.55^{\circ}$. Although three distinct Pt-Cl bond distances are observed, all values are in the same range within experimental error and do not give conclusive evidence of the relative strength of these bonds. The main distortion from the ideal octahedral coordination is due to the small bite angle of the metallacycles $\left(80.9(2)^{\circ}\right)$. The metallacycle is flat and nearly coplanar with both the coordination plane and the mean plane of the (N,N') chelate. A comparison of the bond distances with those for previously reported PtII compound 1-Cl reveals [34] that the equatorial Pt-Cl, Pt-Namine and Pt-C bond lengths are moderately longer, and the Pt-Nimine bond length decreases for the PtIV compound. As a result, the Pt-Namine distance is consistently longer than the Pt-Nimine distance, which suggests a weaker bond with the NMe2 moiety.

The 1H NMR spectrum of compound 2-Cl-Cl in $\mathrm{CDCl} 3$ show the features expected, in particular both $\mathrm{NMe} 2$ and imine protons are coupled with platinum and the $\mathrm{J}(\mathrm{H}-\mathrm{Pt})$ values are smaller than those of the parent PtII compound. Analogous results were obtained for the 1H NMR spectrum recorded in d6DMSO; addition of deuterated water to the NMR sample in d6-DMSO did not produce significant changes. Moreover, the addition of an excess of $\mathrm{NaCl}$ did not produce any changes in the NMR spectrum which, in all cases, only shows one set of resonances. Analogous results were obtained for 2-

$163 \mathrm{~F}-\mathrm{Cl}$ and 2-Cl-OH. According to the NMR studies, all three compounds are stable in the DMSO-water 164 media used for the kinetic study. 
PtIV compounds resulting in loss of the axial ligands. As previously observed for non-cyclometallated similar compounds [1], reduction occurs most readily for chlorido than for hydroxido axial ligands (see Table 1 and Fig. 2). In contrast only a small difference of the potential is obtained upon changing a chloro for a fluoro substituent in the meridional [C,N,N'] ligand with the fluoro derivative 2-F-Cl being slightly less stable towards reduction. Consecutive cycles also shown the presence of an oxidation signal around $1.25 \mathrm{~V}$ associated to the oxidation of some reduced platinum complex, as described in similar systems.

The reactivity of the PtIV complexes shown in Scheme 1 with cysteine and methionine have been studied kinetically at $\mathrm{pH}$ values between 6.5 and 8.0, using HEPES buffer at $0.1 \mathrm{M}$ ionic strength (NaClO4); different chloride concentrations were also used, as described in the Experimental section. As it may be expected from the values determined for the reduction potential of the PtIV complexes (see before, Table 1), only the bis-chlorido derivatives of the organometallic skeleton were found to be reactive under the conditions of the study; the bis-hydroxido complexes were unreactive under the same conditions. The lack of reactivity of the bis-hydroxido compound 2-Cl-OH was confirmed by $1 \mathrm{H}$ and mass spectra (see Experimental section) of the residue obtained after reacting for $24 \mathrm{~h}$ with an excess of the biomolecules in a DMSO-water solvent mixture.

Furthermore, although the reaction with cysteine was readily monitored for the chlorido 2-Cl-Cl and 2$\mathrm{F}-\mathrm{Cl}$ derivatives, all attempts to have these complexes reacted with methionine were unsuccessful, the UV-Vis spectrum of the initial bis-chlorido PtIV complexes were found invariable for hours at room temperature at $\mathrm{pH}=7.0$. Fig. 3a shows the typical spectral changes observed for the chlorido reacting systems (2-Cl-Cl and 2-F-Cl). From the time-resolved spectral changes, and using the Specfit or ReactLab software, two consecutive steps could be assigned to the reactivity sequence observed. The pattern of the spectral changes agrees with an initial PtIV to PtII reduction (decrease of the charge transfer band at ca. $300 \mathrm{~nm}$ and increase of that at ca. $350 \mathrm{~nm}$ ), followed by a reaction (probably substitution, see below) occurring on the PtII derivative produced.

The values of the pseudo-first order rate constants observed (kobs1=kobs red; kobs $2=$ kobs subst) were found to depend linearly on the cysteine concentration, as well as on $\mathrm{pH}$, as shown in Fig. 3b; no significant intercept has been observed. From these plots the second order rate constants (kred and kPtII subs) indicated in Table 2 were obtained, and from its dependence with temperature and pressure the thermal and pressure activation parameters, also shown, were derived. 
201 plus chloride, and the corresponding [PtIICl2(NN)] compounds, the reactivity of the corresponding PtII

202 reduced complexes 1-Cl and 1-F with cysteine was also pursued. In all cases the spectral changes

203 observed for the reaction of the compounds with cysteine at $\mathrm{pH}=7.0$, under the same conditions than

204 those used for the reduction of the PtIV complexes, match exactly with the second step observed. Even

205 the rate constants derived agree within error with those obtained for kobs2, being thus clear that the full

206 process shown in Fig. 3a corresponds to the expected sequence of reduction reaction plus substitution

207 indicated above Scheme 2). The associative character of the activation for the substitution process is also 208 corroborated by the thermal and pressure activation parameters associated, shown in Table 2 (low $\Delta \mathrm{H} \neq$ 209 and very negative $\Delta S \neq$ and $\Delta V \neq$ ). Interestingly, the differences in the values of $\Delta H \neq$ and $\Delta S \neq$ for the 210 substitution processes can only be associated with changes at the peripheral site of the bound ligand.

211 This fact suggests that the resonance effect of fluorine is de facto increasing the electron density of the

212 platinum centre in the para position, thus making the substitution processes less associative (higher $\Delta \mathrm{H} \neq$ 213 and less negative $\Delta \mathrm{S} \neq$ ). The product of the reaction of the PtII compound 1-Cl with cysteine in DMSO214 water mixtures was too insoluble to be characterised by $1 \mathrm{H}$ NMR, but the final residue obtained after 215 reacting for $24 \mathrm{~h}$ a 1:2 (PtIV:cysteine) mixture was analysed by ESI (+)-MS $\{\mathrm{H} 2 \mathrm{O}: \mathrm{CH} 3 \mathrm{CN}(1: 1)\}$. Its 216 mass spectra shows a peak at 539.0926 with an isotopic distribution corresponding to $217[\mathrm{Pt}(\mathrm{CNN})($ cysteine) $]$ (calc. for $\mathrm{C} 15 \mathrm{H} 23 \mathrm{ClN} 3 \mathrm{O} 2 \mathrm{PtS} 539.043)[\mathrm{M}-\mathrm{Cl}+\mathrm{cys}]+$.

218 The dependence of the second order rate constants of the PtIV complexes reduction, as well as those for 219 the PtII substitution, on $\mathrm{pH}$ was also studied for a comprehensive understanding of the reactivity 220 observed. The $\mathrm{pH}$-dependence is similar for both processes, and is associated with the deprotonation of 221 the -SH group of cysteine at pHs close to its $\mathrm{pKa}(\approx 8.0)$; Fig. 4a shows the trend observed for the 222 reduction process as an example. No further quantification of these trends has been carried out due to the 223 fact that $\mathrm{pKa}$ values are much higher than the physiological $\mathrm{pH}$ range where the systems have been 224 studied, Fig. 4a being the initial branch of a typical pKa titration curve. With respect to the dependence 225 on chloride added to the reaction medium, Fig. $4 \mathrm{~b}$ indicates clearly that for the PtIV complex reduction process no significant dependence is observed, in line with the absence of substitution reactions occurring on PtIV compounds containing a single Pt-C bond within the reduction time range [38-40].

\subsection{Reaction with glutathione}

230 Once the reduction of the PtIV complexes with cysteine was found relevant for the generation of more substitutionally active organometallic PtII complexes, the use of glutathione (another reducing biomolecule) was also studied with complex 2-Cl-Cl using the same methodology. Given the fact that the biomolecule reacts with DMSO (in DMSO-water mixtures as those used in this study), the concentration conditions to be used had to be carefully screened. Effectively, under the concentration conditions used for the reaction with cysteine, although the reduction process from PtIV is obvious from 
the pattern of the $\mathrm{UV}-\mathrm{V}$ is spectral changes, the process is masked by a secondary slower reaction, occurring even in the absence of the platinum complex. As a consequence, the platinum complex and glutathione concentrations were diminished to $25-33 \%$ of those previous used. Under these conditions a clearly defined PtIV to PtII process is observed (kobs=kobs red, Fig. 5a), which could be resolved from the secondary glutathione- DMSO/water reaction, observed as a small drift in the final absorbance readings as described in the Experimental section (Fig. 5a, inset). Fig. 5b collects the linear dependence of the pseudo-first order rateconstants for reaction with concentration of the reductant, chloride and $\mathrm{pH}$. The trends observed fully agree with those of the reaction with cysteine with no significant intercept observed. In order to ascertain any possible substitution by glutathione on the PtII reduced complex, the reaction of the PtII complex 1-Cl with glutathione was pursued under the same concentration conditions at $\mathrm{pH}=7.0$ and $25^{\circ} \mathrm{C}$. Fig. $5 \mathrm{~b}$ also shows the glutathione concentration dependence observed for this process, kobs=kobs subs. Interestingly, the substitution reaction monitored is much faster than the reduction process indicated above, which implies that the final product upon reduction of the 2-Cl-Cl PtIV is, de facto, the 1-Cl PtII substituted complex. Table 3 collects the relevant kinetic and thermal activation parameters for the two series of reactions observed.

\subsection{Reaction with thiolactic acid}

253 Finally the reaction on compound 2-Cl-Cl with a smaller and less acidic thiol with no amine groups, thiolactic acid, was also tried at $\mathrm{pH}=7.0$. The purpose was to study the possible changes of activity due to its $\mathrm{pKa}$, the effect of the absence of amine groups in the biomolecule, and the possible chelation on the final reduced 1-Cl PtII complex formed. As a whole, the time-resolved spectral changes proved to be much slower, and much more complex, than for the systems studied before, once the parent PtII 1-Cl complex was considered. For the simple reduction reaction of the 2Cl-Cl PtIV compound, a final decomposition of the biomolecule under the conditions of the study had to be quantified in the absence of PtIV compound (and further eliminated as explained in the Experimental section from the reactivity pattern) as already done for the glutathione molecule. Even under these conditions, though, the spectral pattern of a single PtIV to PtII reduction reaction was clearly observed (Fig. 6a), and the corresponding pseudo-first order rate constants, kobs=kobs red, were derived by the standard Specfit or ReactLab software $[41,42]$. From its linear variation with thiolactic concentration, the values of kred at different temperatures (Fig. 6b) and pressures were derived, as well as the associated activation parameters at $\mathrm{pH}=7.0$ (Table 4).

In view of the data obtained, it is clear that either no reaction of thiolactic acid occurs on the 1-Cl PtII reduced compound or this is faster that the reduction process determined, as found for glutathione (see before). Consequently the reaction of the PtII complex with thiolactic acid under the same conditions was pursued (avoiding the final decomposition of the biomolecule). Fig. 7a shows the spectral changes 
271 associated with a set of two consecutive reactions observed; in Fig. 7b the dependence of the derived

272 two pseudo-first order rate constants, kobs1 and kobs2 (kobs subst1 and kobs subst2), on the thiolactic

273 acid concentration are also shown at $\mathrm{pH}=7.0$ and $25^{\circ} \mathrm{C}$. Table 4 collects also the summary of these data.

274 From the data is seems clear that the process associated with kobs1 is a clearly defined substitution

275 process on the PtII 1-Cl species. Nevertheless, the reaction associated with kobs2 has to correspond to a

276 chelation of the thiolactic molecule on the PtII species independent on the concentration of ligand; the

277 smaller bite angle with the already deprotonated carboxylate moiety of the molecule can easily explain 278 this fact.

279 
282 From the data collected in the Results section (plus the available data corresponding to the acidity and redox characteristics at $\mathrm{pH}=7.0$ of the free biomolecules used in this study and collected in Table 5), it is clear that the observed lack of reactivity of the methionine molecules with the PtIV complexes could not be associated with the reduction potential. Methionine is, in fact, the most readily oxidised of the thiol derivatives used [43], which indicates, as stated before, that the thermodynamic oxidation of these biomolecules does not correspond to the processes by which the reduction of PtIV complexes are reduced $[16-18,44]$. Neither the formation of SeS bonds nor sulfoxide formation are relevant for the reaction observed, the process being already described as a reductive elimination $\mathrm{S}-\mathrm{Cl}$ reaction occurring on the PtIV starting material (Scheme 2) [17]. The fastest reaction observed corresponds, in fact, to the less thermodynamically favourable redox process, thus reinforcing the importance of the study of the proper mechanistic reaction paths for biologically relevant reactivity [45].

The only clear reactivity trend observed within the data collected corresponds to that associated with acidity changes of the biomolecules. The reaction rates for the reduction process increase on increasing the amount of thiolate present in the reaction medium at $\mathrm{pH} 7.0$ [16-18]; even so, the amount of free thiolate units at the physiological $\mathrm{pH}$ range studied is rather small thus indicating the high reactivity involved (see Table 5). This fact is in line with the expected, provided an attack of the thiolate group on a chlorido ligand to produce the reductive elimination of $\mathrm{RSCl}$ is the responsible of the reduction process (see Fig. 4a and Scheme 2). Taking this fact into account the lack of reactivity observed with methionine, despite the highly favourable potential, can be easily related with its thioether nature that does not allow for a thiolate attack to the bound chlorido ligand. In this line, the values of the entropies and volumes of activation are rather negative due to the ordering (and contraction) of an external thiolcontaining molecule when interacting with the chlorido ligand to produce the leaving -SCl unit; the reaction being de facto the reverse of a SN2 oxidative addition process. The effect of the intra- and extra-cellular chloride concentration gradient has been found to be irrelevant for the redox reactivity observed, thus indicating that no chlorido aquation from the PtIV complexes is occurring during the reactivity studied. Thus the fact that the original PtIV complex keeps as such before the reduction process studies is reinforced, in important contrast with what occurs with the cisplatin analogues [45]. parameters when the amine groups present in cysteine and glutathione are absent, as in thiolactic acid (see Table 5). The value on the activation enthalpy decreases noticeably, while the entropy and volume of activation become much more negative. Given the fact that the difference in pKa between cysteine and glutathione is of the same magnitude than that between glutathione and thiolactic acid, and that only minimal reactivity changes are observed, this effect cannot be related solely to acidity tuning. Clearly a higher degree of ordering and contraction is occurring for the RSH group to reach the chlorido ligand 
316 (producing simultaneously a less enthalpy demanding $\mathrm{RSCl}$ reductive elimination) on its way to the

317 final PtII complex with this biomolecule. Taking into account that the final PtII reduced complex has

318 been proved kinetically to contain a thiolactate chelate unit (see Results section), probably the bite angle

319 of this biomolecule allows for an extra Pt-O interaction with the reducing PtIV centre when losing one

320 of the axial chlorido groups on reduction [19].

321 In this respect the study of the substitution processes of the resulting 1-Cl PtII complex with the same

322 biomolecules, and under the same $\mathrm{pH}$ and concentration conditions, has been extremely revealing. Only

323 for cysteine the substitution process has been found slower than that of reduction (see Table 2), thus

324 allowing for the reduced 1-Cl complex to associatively discriminate between the ligands present in the

325 reaction medium even in the presence of the soft thiol containing biomolecule. The process is clearly

326 associatively activated [40], as expected for a square planar complex containing a single Pt-C bond, and

327 as also indicated by the activation parameters collected [54]. For glutathione and thiolactic acid the

328 substitution reaction on complex 1-Cl is ca. one order of magnitude faster than the reduction reaction

329 (see Tables 3 and 4) which implies that the PtII species resulting from the reduction of the PtIV

330 precursor may very well have the biomolecule already coordinated. In this case the final compound,

331 although being discriminating due to the associative substitution mechanism expected to be operating

332 for these organometallic single Pt-C containing complexes [40], has a definitive clear kinetic preference

333 for these two biomolecules, thus affecting an effective selective coordination with the rest of bioligands

334 that could be present in the reaction medium. 
338 Only the tris-chlorido derivatives from the cyclometallated skeleton indicated in Scheme 1 can be 339 reduced by cysteine, glutathione and thiolactic acid. The mono-chlorido, bis-hydroxido derivatives from 340 the same cyclometallated unit are not reduced due to the high potential of the PtIV/PtII pair, as measured

341 in aqueous solution. The reduction reaction is found to be clearly dependent on the amount of 342 deprotonated thiolate present in the medium, which agrees with a reductive elimination process involving an attack of thiolate to one of the chloride ligands to produce RSCl. No intervening chlorido substitution reactions are involved during this process, thus ensuring the maintenance of the PtIV complex structure before its reduction. The thermal and pressure activation parameters agree with this assumption, as well as the fact that methionine is found unreactive under the same conditions, despite the more favourable redox potential. Interestingly for the reduction reaction with thiolactic acid an unexpected increase in ordering and contraction is observed from the data collected; the fact that the ligand can actuate as a perfect chelating unit to one of the other PtIV coordination positions losing a chlorido ligand can be held responsible for this fact.

351 The study of the substitution reactions occurring at the $\left[\mathrm{PtII}\left(\mathrm{CNN}^{\prime}\right) \mathrm{Cl}\right]$ reduced species has also

352 provided support for the reactivity observed. While for the reduction with cysteine, the PtII complex can

353 be detected in solution under the conditions of the study, for the reduction with glutathione and thiolactic acid the consecutive substitution process is very fast. For these reactions the final PtII complex after reduction already has the reducing agent present in solution coordinated to the metal centre (even in a chelate fashion for thiolactic acid reduction). Despite the associativeness character of the substitution reactions occurring on these single Pt-C containing organometallic complexes, these reactions become less capable of distinguishing between ligands. The thermal and pressure activation

359 parameters of the substitution reaction have been determined for the reaction with cysteine provides

360 further corroboration of the latter assumption.

361 The results obtained confirm the expected reactivity sequence of the PtIV compounds with thiols 362 consisting of reduction and substitution, and, in addition, the present study reveals that the relative rates of these reactions are relevant for the design of more efficient PtIV prodrugs. 


\section{EXPERIMENTAL}

5.1. General

Microanalyses were performed at the Centres Científics i Tecnològics (Universitat de Barcelona). Mass spectra were performed at the Unitat d'Espectrometria de Masses (Universitat de Barcelona) in a LC/MSD-TOF spectrometer using H2O-CH3CN 1:1 to introduce the sample. NMR spectra were performed at the Unitat de RMN d'Alt Camp de la Universitat de Barcelona using a Mercury-400 $(1 \mathrm{H}$, $400 \mathrm{MHz}$; 13C, 100.6 MHz; 19F, 376.5 MHz) or a Bruker 400 MZ AvanceIII Avance (1H, $400 \mathrm{MHz})$ and referenced to SiMe4 (1H and 13C) or $\mathrm{CFCl} 3(19 \mathrm{~F}) . \delta$ values are given in ppm and J values in $\mathrm{Hz}$. Abbreviations used: $\mathrm{s}=$ singlet; $\mathrm{d}=$ doublet; $\mathrm{t}=$ triplet; $\mathrm{m}=$ multiplet; $\mathrm{sh}=$ shoulder.

375

5.2. Compounds

$[\mathrm{PtCl} 3\{(\mathrm{CH} 3) 2 \mathrm{~N}(\mathrm{CH} 2) 3 \mathrm{NCH}(4-\mathrm{ClC} 6 \mathrm{H} 3)\}](2-\mathrm{Cl}-\mathrm{Cl})$ was obtained from $0.050 \mathrm{~g}(0.090 \mathrm{mmol})$ of the cyclometallated $[\mathrm{PtCl}\{(\mathrm{CH} 3) 2 \mathrm{~N}(\mathrm{CH} 2) 3 \mathrm{NCH}(4-\mathrm{ClC} 6 \mathrm{H} 3)\}]$ and the equimolar amount of $\mathrm{PhICl} 2$ in acetone $(15 \mathrm{~mL})$ following the method described in the literature for similar compounds [37]. Yield: 35 mg (60\%). 1H NMR (400 MHz, CDCl3): $\delta=8.22[\mathrm{~s}, 3 \mathrm{~J}(\mathrm{Pt}-\mathrm{H})=8.0,1 \mathrm{H}, \mathrm{He}], 8.05[\mathrm{~d}, 4 \mathrm{~J}(\mathrm{HeH})=2.0$, $3 \mathrm{~J}(\mathrm{Pt}-\mathrm{H})=24.0,1 \mathrm{H}, \mathrm{Hh}], 7.43[\mathrm{~d}, 3 \mathrm{~J}(\mathrm{HeH})=8.0,1 \mathrm{H}, \mathrm{Hf}], 7.23[\mathrm{dd}, 3 \mathrm{~J}(\mathrm{HeH})=8.0,4 \mathrm{~J}(\mathrm{HeH})=2.0,1 \mathrm{H}, \mathrm{Hg}]$, $4.00[\mathrm{~m}, 2 \mathrm{H}, \mathrm{Hd}], 2.97$ [s, 3J(Pt- H)=11.2, 6H, Ha], $2.95[\mathrm{~m}, 2 \mathrm{H}, \mathrm{Hb}], 2.26$ [q, 3J(HeH)=4.8.0, 2H, Hc]. 1H NMR (400 MHz, d6-DMSO): $\delta=8.79$ [s, 3J(Pt-H)=96.0, 1H, He], 7.69 [d, 4J(HeH)=2.0, 1H, Hh], $7.69[\mathrm{~d}, 3 \mathrm{~J}(\mathrm{HeH})=8.0,1 \mathrm{H}, \mathrm{Hf}], 7.37[\mathrm{dd}, 3 \mathrm{~J}(\mathrm{HeH})=8.0,4 \mathrm{~J}(\mathrm{HeH})=2.0,1 \mathrm{H}, \mathrm{Hg}], 3.95[\mathrm{~m}, 2 \mathrm{H}, \mathrm{Hd}], 2.8 .05$ [m, 2H, Hb], 2.8.00 [s, 3J(Pt-H) ca. 8.0 (sh), 6H, Ha], 2.06 [m, 2H, Hc]. 13C NMR (100.6 MHz, d6DMSO): $\delta=178.03$ [Ce], 141.63, 140.42, 136.61, 132.10 [Cf], $131.41[\mathrm{Ch}], 126.76[\mathrm{Cg}], 62.11[\mathrm{Cb}]$, 57.29 [Cd], 49.79 [Ca], 25.21 [Cc]. Anal. Calc. for C12H16Cl4N2Pt (\%): C, 27.45; H, 3.07; N, 5.33. Found (\%): C, 27.27; H, 3.02; N, 5.15.

$[\mathrm{PtCl}(\mathrm{OH}) 2\{(\mathrm{CH} 3) 2 \mathrm{~N}(\mathrm{CH} 2) 3 \mathrm{NCH}(4-\mathrm{ClC} 6 \mathrm{H} 3)\}](2-\mathrm{Cl}-\mathrm{OH})$ was obtained from $0.050 \mathrm{~g}(0.090 \mathrm{mmol})$ of the cyclometallated $[\mathrm{PtCl}\{(\mathrm{CH} 3) 2 \mathrm{~N}(\mathrm{CH} 2) 3 \mathrm{NCH}(4-\mathrm{ClC} 6 \mathrm{H} 3)\}]$ and the equimolar amount of $\mathrm{H} 2 \mathrm{O} 2$ in dichloromethane $(15 \mathrm{~mL})$ following the method described in the literature for similar compounds [36]. Yield: $27 \mathrm{mg}$ (50\%). 1H NMR (400 MHz, CDCl3): $\delta=8.30$ [s, 3J(Pt-H)=108.0, 1H, He], 8.00 [d, 4J $(\mathrm{HeH})=2.0,3 \mathrm{~J}(\mathrm{Pt}-\mathrm{H})=28.0,1 \mathrm{H}, \mathrm{Hh}], 7.41[\mathrm{~d}, 3 \mathrm{~J}(\mathrm{HeH})=8.0,1 \mathrm{H}, \mathrm{Hf}], 7.26[\mathrm{dd}, 3 \mathrm{~J}(\mathrm{HeH})=8.0$, $4 \mathrm{~J}(\mathrm{HeH})=2.0,1 \mathrm{H}, \mathrm{Hg}], 3.98 .0[\mathrm{t}, 3 \mathrm{~J}(\mathrm{HeH})=5.2,2 \mathrm{H}, \mathrm{Hd}], 2.91[\mathrm{~m}, 2 \mathrm{H}, \mathrm{Hb}], 2.78 .0[\mathrm{~s}, 6 \mathrm{H}, \mathrm{Ha}], 2.17[\mathrm{~m}$, 2H, Hc]. 1H NMR (400 MHz, d6-DMSO): $\delta=8.46[\mathrm{~s}, 3 \mathrm{~J}(\mathrm{Pt}-\mathrm{H})=104.0,1 \mathrm{H}, \mathrm{He}], 7.75[\mathrm{~d}, 4 \mathrm{~J}(\mathrm{HeH})=2.0$, $1 \mathrm{H}, \mathrm{Hh}], 7.52[\mathrm{~d}, 3 \mathrm{~J}(\mathrm{HeH})=8.0,1 \mathrm{H}, \mathrm{Hf}], 7.28 .0[\mathrm{dd}, 3 \mathrm{~J}(\mathrm{HeH})=8.0,4 \mathrm{~J}(\mathrm{HeH})=2.0,1 \mathrm{H}, \mathrm{Hg}], 3.8 .02[\mathrm{~m}$, 2H, Hd], 2.76 [m, 2H, Hb], 2.56 [s, 6H, Ha], 1.98 .0 [m, 2H, Hc]. 13C NMR (100.6 MHz, d6-DMSO): $\delta=178.33$ [Ce], 143.32, 142.77, 135.35, 131.64 [Cf], 131.13 [Ch], 125.94 [Cg], 62.05 [Cb], 57.12 [Cd], 
426

$47.44[\mathrm{Ca}], 25.02$ [Cc]. ESI(+)-MS \{H2O:CH3CN (1:1)\}, m/z: 471.0343 (calc. for C12H17Cl2N2OPt 471.0444) $[\mathrm{M}-\mathrm{OH}]+, 48.09 .0448 .0$ (calc. for $\mathrm{C} 12 \mathrm{H} 19 \mathrm{Cl} 2 \mathrm{~N} 2 \mathrm{O} 2 \mathrm{Pt} 48.09 .0449)[\mathrm{M}+\mathrm{H}]+$. Anal. Calc. for $\mathrm{C} 12 \mathrm{H} 18.0 \mathrm{Cl} 2 \mathrm{~N} 2 \mathrm{O} 2 \mathrm{Pt} \cdot \mathrm{CH} 2 \mathrm{Cl} 2$ (\%): C, 27.24; H, 3.52; N, 4.8.09. Found (\%): C, 27.04; H, 3.30; N, 5.27. [PtCl3 $\{(\mathrm{CH} 3) 2 \mathrm{~N}(\mathrm{CH} 2) 3 \mathrm{NCH}(4-\mathrm{FC} 6 \mathrm{H} 3)\}](2-\mathrm{F}-\mathrm{Cl})$ was obtained from $0.050 \mathrm{~g}(0.090 \mathrm{mmol})$ of the cyclometallated $[\mathrm{PtCl}\{(\mathrm{CH} 3) 2 \mathrm{~N}(\mathrm{CH} 2) 3 \mathrm{NCH}(4-\mathrm{FC} 6 \mathrm{H} 3)\}]$ and the equimolar amount of $\mathrm{PhICl} 2$ in acetone $(15 \mathrm{~mL})$ following the method described in the literature for similar compounds [37]. Yield: 33 mg (57\%). 1H NMR (400 MHz, d6-DMSO): $\delta=8.74$ [s, 3J(Pt-H)=96.0, 1H, He], 7.77 [dd, 3J(HeH)=8.4, $4 \mathrm{~J}(\mathrm{HF})=6.0,1 \mathrm{H}, \mathrm{Hf}], 7.43[\mathrm{dd}, 3 \mathrm{~J}(\mathrm{H}-\mathrm{F})=9.6,4 \mathrm{~J}(\mathrm{HeH})=2.0,1 \mathrm{H}, \mathrm{Hh}], 7.14[\mathrm{td}, 3 \mathrm{~J}(\mathrm{HeH})=3 \mathrm{~J}(\mathrm{H}-\mathrm{F})=8.4$, $4 \mathrm{~J}(\mathrm{HeH})=2.0,1 \mathrm{H}, \mathrm{Hg}], 3.94[\mathrm{~m}, 2 \mathrm{H}, \mathrm{Hd}], 2.8 .06[\mathrm{~m}, 2 \mathrm{H}, \mathrm{Hb}], 2.8 .00[\mathrm{~s}, 6 \mathrm{H}, 3 \mathrm{~J}(\mathrm{Pt}-\mathrm{H})=8.0, \mathrm{Ha}], 2.06[\mathrm{~m}$, 2H, Hc]. 19F NMR (376.5 MHz, d6-DMSO): $\delta=-100.73$ [td, 3J(FH)=9.0, 4J(F-H)=5.9]. Anal. Calc. for C12H16Cl3FN2Pt (\%): C, 28.33; H, 3.17; N, 5.51. Found (\%): C, 28.32; H, 3.24; N, 5.32.

\subsection{Instruments and methods}

Buffer solutions were prepared using the standard procedures using HEPES; in all cases the concentration of the buffer was at least 10 -fold $(0.01 \mathrm{M})$ that of the reactants and the ionic strength was set at 0.1 with $\mathrm{NaClO} 4$.

Electrochemistry experiments were carried out with a BioLogic SP- 150 instrument using a glassy carbon working electrode, a $\mathrm{Ag} / \mathrm{AgCl}(3 \mathrm{M} \mathrm{KCl})$ reference electrode, and platinum wire counter electrode; potential values are given versus SHE. The samples were dissolved in 1:1 a water-DMSO mixture at the $1 \times 10-3 \mathrm{M}$ level concentration and using $0.1 \mathrm{M}(\mathrm{Bu} 4 \mathrm{~N}) \mathrm{ClO} 4$ as supporting electrolyte.

\subsection{X-ray diffraction}

Suitable crystals of compound 2-Cl-Cl were grown at room temperature in dichloromethane-methanol. X-ray diffraction data were collected for a yellow prism-like specimen on a D8.0 VENTURE system equipped with a multilayer monochromator and a Mo microfocus source $(\lambda=0.71073 \AA)$ at $100 \mathrm{~K}$. The structures were solved and refined using the Bruker SHELXTL Software package [55]; crystallographic details are given in CCDC 1828170.

\subsection{Kinetics}

The time-resolved kinetic profiles for the reactions at ambient pressure with were followed by UV-Vis spectroscopy in the full $700-275 \mathrm{~nm}$ range on HP8.0453 or Cary50 instruments equipped with thermostated multicell transports. For runs carried out at elevated pressures the evolutions of the systems 
431 were followed with an already described pressurizing cell system setup was used connected to a TIDAS

432 J\&M instrument. The general technique used for these experiments where a linear dependence on the

433 concentration is observed has already been described [56]. The kinetic experiments were conducted

434 under pseudo-first order conditions by mixing the appropriate amounts of aqueous buffer stock solution,

$4350.1 \mathrm{M} \mathrm{NaClO} 4$ (or $0.1 \mathrm{M} \mathrm{NaCl}$ ) aqueous solutions, aqueous solution of the appropriate reductant, water,

436 DMSO, and a stock solution of the PtIV complex in neat DMSO. In all cases the final DMSO volume

437 percentage of the solutions was $20 \%$ to allow the full solution of the PtIV complexes used. Observed

438 rate constants were derived from the absorbance versus time traces at the wavelengths where a

439 maximum increase and/or decrease of absorbance were observed. Calculation of the observed rate

440 constants from the absorbance versus time monitoring of reactions were carried out using the SPECFIT

441 or ReactLab software packages [40,41]. In all cases the systems were set to a single: $\mathrm{A} \rightarrow \mathrm{B}$ or a two:

$442 \quad \mathrm{~A} \rightarrow \mathrm{B} \rightarrow \mathrm{C}$ step scheme. For systems showing a final drift of the absorbance due to undesired

443 decomposition processes of the reductant in the reaction medium, a final linear drift step was also

444 included for final refinement. All post-run fittings were carried out by the standard available commercial 445 programs. 


\section{ACKNOWLEDGEMENTS}

448

449 Financial support from the Spanish Ministerio de Economía y Competitividad (project CTQ2015-

450 65707C2-1/FEDER;CTQ2015-65040-P; CTQ2017-90802-REDT) is acknowledged. PH also

451 acknowledges Shiraz University for a $\mathrm{PhD}$ travel Grant

452 
454 [2] D. Gibson, Dalton Trans. 45 (2016) 12983-12991.

455 [3] T.C. Johnstone, J.J. Wilson, S.J. Lippard, Inorg. Chem. 52 (2013) 12234-12249.

456 [4] R.G. Kenny, S.W. Chuah, A. Crawford, C.J. Marmion, Eur. J. Inorg. Chem. 2017 (2017) 1596-1612.

457 [5] L. Cai, C. Yu, L. Ba, Q. Liu, Y. Qian, B. Yang, C. Gao, Appl. Organomet. Chem. 32 (2018) e4228.

458 [6] B.J. Pages, K.B. Garbutcheon-Singh, J.R. Aldrich-Wright, Eur. J. Inorg. Chem. 2017 (2017) 16134591624.

460 [7] M.R. Reithofer, A.K. Bytzek, S.M. Valiahdi, C.R. Kowol, M. Groessl, C.G. Hartinger, M.A. Jakupec, M. Galanski, B.K. Keppler, J. Inorg. Biochem. 105 (2011) 46-51.

463

[8] J.J. Wilson, S.J. Lippard, Chem. Rev. 114 (2014) 4470-4495.

464

[9] S.Q. Yap, C.F. Chin, A.H. Hong Thng, Y.Y. Pang, H.K. Ho, W.H. Ang, ChemMedChem 12 (2017) 300-311.

465

[10] V. Reshetnikov, S. Daum, A. Mokhir, Chemistry A Eur. J. 23 (2017) 5678-5681.

466

[11] I. Ritacco, G. Mazzone, N. Russo, E. Sicilia, Inorg. Chem. 55 (2016) 1580-1586.

[12] T.C. Johnstone, K. Suntharalingam, S.J. Lippard, Chem. Rev. 116 (2016) 3436-3486.

[13] L.T. Ellis, H.M. Er, T.W. Hambley, Aust. J. Chem. 48 (1995) 793-806.

[14] S. Choi, C. Filotto, M. Bisanzo, S. Delaney, D. Lagasee, J.L. Whitworth, A. Jusko, C. Li, N.A.

Wood, J. Willingham, A. Schwenker, K. Spaulding, Inorg. Chem. 37 (1998) 2500-2504.

[15] Y. Nakabayashi, A. Erxleben, U. Létinois, G. Pratviel, B. Meunier, L. Holland, B. Lippert, Chem. A Eur. J. 13 (2007) 3980-3988.

473 [16] E. Wexselblatt, D. Gibson, J. Inorg. Biochem. 117 (2012) 220-229.

474 [17] M. Sinisi, F.P. Intini, G. Natile, Inorg. Chem. 51 (2012) 9694-9704.

475 [18] J.Z. Zhang, E. Wexselblatt, T.W. Hambley, D. Gibson, Chem. Commun. 48 (2012) 847-849.

476 [19] S. Jovanovic, B. Petrovic, Z.D. Bugarcic, R. van Eldik, Dalton Trans. 42 (2013) 8890-8896.

477 [20] Y. Shi, S.A. Liu, D.J. Kerwood, J. Goodisman, J.C. Dabrowiak, J. Inorg. Biochem. 107 (2012) 6$478 \quad 14$.

479 [21] E. Volckova, E. Weaver, R.N. Bose, Eur. J. Med. Chem. 43 (2008) 1081-1084.

480 [22] P. Zhang, P.J. Sadler, Eur. J. Inorg. Chem. (2017) 1541-1548.

481 [23] C.G. Hartinger, N. Metzler-Nolte, P.J. Dyson, Organometallics 31 (2012) 5677-5685.

482 [24] G. Gasser, I. Ott, N. Metzler-Nolte, J. Med. Chem. 54 (2011) 3-25.

483 [25] A.L. Noffke, A. Habtemariam, A.M. Pizarro, P.J. Sadler, Chem. Commun. 48 (2012) 5219-5246.

484 [26] I. Omae, Coord. Chem. Rev. 280 (2014) 84-95.

485 [27] E. Bauer, X. Domingo, C. Balcells, I.H. Polat, M. Crespo, J. Quirante, J. Badia, L. Baldoma, M. Font-Bardia, M. Cascante, Dalton Trans. 46 (2017) 14973-14987. 
[28] G. Aullón, M. Crespo, J. Jover, M. Martínez, Vol 70 ed. Rudi van Eldik, Colin Hubbard (Eds.), Advances in Inorganic Chemistry Inorganic Reaction Mechanisms, Academic Press, 2017, pp. 195-242.

[29] T. Shi, J. Berglund, I. Elding, J. Chem. Soc., Dalton Trans. (1997) 2073-2078.

[30] J. Dong, Y. Ren, S. Huo, S. Shen, J. Xu, H. Tian, T. Shi, Dalton Trans. 45 (2016) 11326-11337.

[31] K. Lemma, J. Berglund, N. Farrell, L.I. Elding, J. Biol. Inorg. Chem. 5 (2000) 300-306.

[32] T. Shi, J. Berglund, L.I. Elding, Inorg. Chem. 35 (1996) 3498-3503.

[33] J. Dong, S. Huo, S. Shen, J. Xu, T. Shi, L.I. Elding, Bioorg. Med. Chem. Lett. 26 (2016) 42614266.

[34] A. Capapé, M. Crespo, J. Granell, M. Font-Bardía, X. Solans, J. Organomet. Chem. 690 (2005) 4309-4318.

[35] A. Gandioso, J. Valle-Sistac, L. Rodríguez, M. Crespo, M. Font-Bardia, Organometallics 33 (2014) $561-570$.

[36] K.A. Thompson, C. Kadwell, P.D. Boyle, R.J. Puddephatt, J. Organomet. Chem. 829 (2017) 22-30.

[37] T.C. Johnstone, S.M. Alexander, J.J. Wilson, S.J. Lippard, Dalton Trans. 44 (2015) 119-129.

[38] P.V. Bernhardt, C. Gallego, M. Martínez, Organometallics 19 (2000) 4862-4869.

[39] C. Gallego, G. González, M. Martínez, A.E. Merbach, Organometallics 23 (2004) 2434-2438.

[40] U. Frey, L. Helm, A.E. Merbach, R. Romeo, J. Am. Chem. Soc. 111 (1989) 8161-8165.

[41] R.A. Binstead, A.D. Zuberbuhler, B. Jung, SPECFIT32. [3.0.34], Spectrum Software Associates, Marlborough, MA, USA,, 2005.

[42] M. Maeder, P. King, ReactLab, Jplus Consulting Pty Ltd, East Fremantle, WA. Australia, 2009.

[43] J. Bergès, P. de Oliveira, I. Fourré, C. Houée-Levin, J. Phys. Chem. B 116 (2012) 9352-9362.

[44] F. Sebesta, K. Baxová, J.V. Burda, Inorg. Chem. 57 (2018) 951-962.

[45] J. Molas Saborit, A. Caubet, R.F. Brissos, L. Korrodi-Gregorio, R. Perez-Tomas, M. Martínez, P. Gamez, Dalton Trans. 46 (2017) 11214-11222.

[46] D.E. Green, Biochem. J 27 (1933) 678.

[47] F. Krekel, A.K. Samland, P. Macheroux, N. Amrhein, J.N.S. Evans, Biochemistry 39 (2000) 12671-12677.

[48] J.T. Edsall, J. Wyman, Biophysical Chemistry vol. 1, Academic Press, 1958.

[49] H. Kimura, G. Ishihara, S. Tajima, J. Biochem. 120 (1996) 1182-1189.

[50] S.G. Tajc, B.S. Tolbert, R. Basavappa, B.L. Miller, J. Am. Chem. Soc. 126 (2004) 10508-10509.

[51] H. Borsook, E.L. Ellis, H.M. Huffman, J. Biol. Chem. 117 (1937) 281-308.

[52] in Applications of Ion Chromatography for Pharmaceutical and Biological Products, John Wiley \& Sons, Inc., 2012, pp. 449-453.

[53] O.H. Emerson, P.L. Kirk, C.L.A. Schmidt, J. Biol. Chem. 92 (1931) 449-452.

[54] M.L. Tobe, J. Burgess, Inorganic Reaction Mechanisms, Longman, 1999.

[55] G.M. Sheldrick, Acta Crystallogr. Sec. A 71 (2015) 3-8. 
524 [56] P.V. Bernhardt, M.A. Gonzálvez, M. Martínez, Inorg. Chem. 56 (2017) 14284-14290. 525 
Scheme 1 Synthesis of the PtIV compounds involved in this study including the numbering scheme for

NMR assignments (see Experimental section).

Figure. 1. Molecular structure of compound 2-Cl-Cl showing 50\% probability ellipsoids; hydrogen atoms were omitted for the sake of clarity. Selected bond lengths $(\AA)$ and angles $\left(^{\circ}\right)$ with estimated standard deviations: $\operatorname{Pt}(1)-\mathrm{C}(1)$ : 2.002(6); $\operatorname{Pt}(1)-\mathrm{Cl}(2)$ : 2.3116(15); $\operatorname{Pt}(1)-\mathrm{N}(1): 2.032(5) ; \operatorname{Pt}(1)-\mathrm{N}(2)$ : 2.259(6); $\mathrm{Pt}(1)-\mathrm{Cl}(3): 2.3192(15) ; \mathrm{Pt}(1)-\mathrm{Cl}(4): 2.3184(15) ; \mathrm{C}(1)-\mathrm{Pt}(1)-\mathrm{N}(1): 80.9(2) ; \mathrm{C}(1)-\mathrm{Pt}(1)-\mathrm{N}(2)$ : 177.0(2); N(1)-Pt(1)-N(2): 96.5(2); C(1)-Pt(1)-Cl(2): 88.22(18); N(1)-Pt(1)-Cl(2): 88.67(15); N(2)Pt(1)-Cl(2): 90.26(15); C(1)-Pt(1)-Cl(4):93.73(19); N(1)-Pt(1)-Cl(4): 174.43(15); N(2)-Pt(1)-Cl(4): 88.95(15); $\mathrm{Cl}(2)-\mathrm{Pt}(1)-\mathrm{Cl}(4)$ : 92.50(6); C(1)-Pt(1)-Cl(3): 86.80(17); N(1)-Pt(1)-Cl(3): 88.35(15); N

Figure. 2. 1st cycle of the cyclic voltammograms of compounds 2-Cl-Cl and 2-Cl-OH in DMSO-water solution at a scan rate of $100 \mathrm{mV} / \mathrm{s}$ and the electrochemical setup described in the Experimental section.

Figure. 3. a) UV-Vis spectral changes obtained on the reaction of PtIV complex 2-F-Cl, $4 \times 10-5 \mathrm{M}$, with cysteine, $4 \times 10-4 \mathrm{M}$, at $\mathrm{pH} 7.0$ and $25^{\circ} \mathrm{C}$. b) Plot of the rate constants derived for the two steps observed (kobs1 and kobs2) for the 2-Cl-Cl complex, $1 \times 10-5 \mathrm{M}$, as a function on the cysteine concentration at different $\mathrm{pH}$ values and $25^{\circ} \mathrm{C}$.

Scheme 2. Reduction plus substitution reactivity sequence expected for the processes studied.

Figure. 4. a) $\mathrm{pH}$-dependence of the second order rate constants for the reduction of the PtIV complexes 2-Cl-Cl and 2-F-Cl at $25{ }^{\circ} \mathrm{C}$. b) Plot of the rate constants obtained for the reduction reaction of the same complex with cysteine as a function of cysteine and chloride concentration at $\mathrm{pH} 7.0$ and $25^{\circ} \mathrm{C}$.

Figure. 5 a) UV-Vis spectral changes obtained on the reaction of PtIV complex $2-\mathrm{Cl}-\mathrm{Cl}, 1 \times 10-5 \mathrm{M}$, with glutathione, $1 \times 10-4 \mathrm{M}$ at $\mathrm{pH} 7.0$ and $25^{\circ} \mathrm{C}$. b) Plot of the pseudo-first order rate constants derived for the reduction observed on complex 2-Cl-Cl (kobs red) at different $\mathrm{pHs}$ (empty square points correspond to $0.1 \mathrm{M} \mathrm{NaCl}$ added), and those of the substitution (kobs subs) occurring on the 1-Cl PtII complex at $\mathrm{pH}=7.0$, with the same ligand and as a function on glutathione concentration at $25^{\circ} \mathrm{C}$. (For interpretation of the references to colour in this figure legend, the reader is referred to the web version of this article.) 
562 Figure. 6 a) UV-Vis spectral changes obtained on the reaction of the PtIV complex 2-Cl-Cl, 1×10-6 M, 563 with thiolactic acid, $1 \times 10-4 \mathrm{M}$ at $\mathrm{pH} 7.0$ and $25^{\circ} \mathrm{C}$. b) Plot of the rate constants derived for the 564 reduction observed on the same complex, kobs=kobs red, at $\mathrm{pH}=7.0$ (empty points correspond to $0.1 \mathrm{M}$ $565 \mathrm{NaCl}$ added) at different temperatures. (For interpretation of the references to colour in this figure 566 legend, the reader is referred to the web version of this article.)

567

568 Figure. 7 a) UV-Vis spectral changes obtained on the reaction of the PtII complex 1-Cl, $3 \times 10-6 \mathrm{M}$, 569 with thiolactic acid, $1 \times 10-4 \mathrm{M}$ at $\mathrm{pH} 7.0$ and $25^{\circ} \mathrm{C}$. b) Plot of the rate constants derived for the two 570 sequential processes observed at $\mathrm{pH}=7.0$ and $25^{\circ} \mathrm{C}$. 

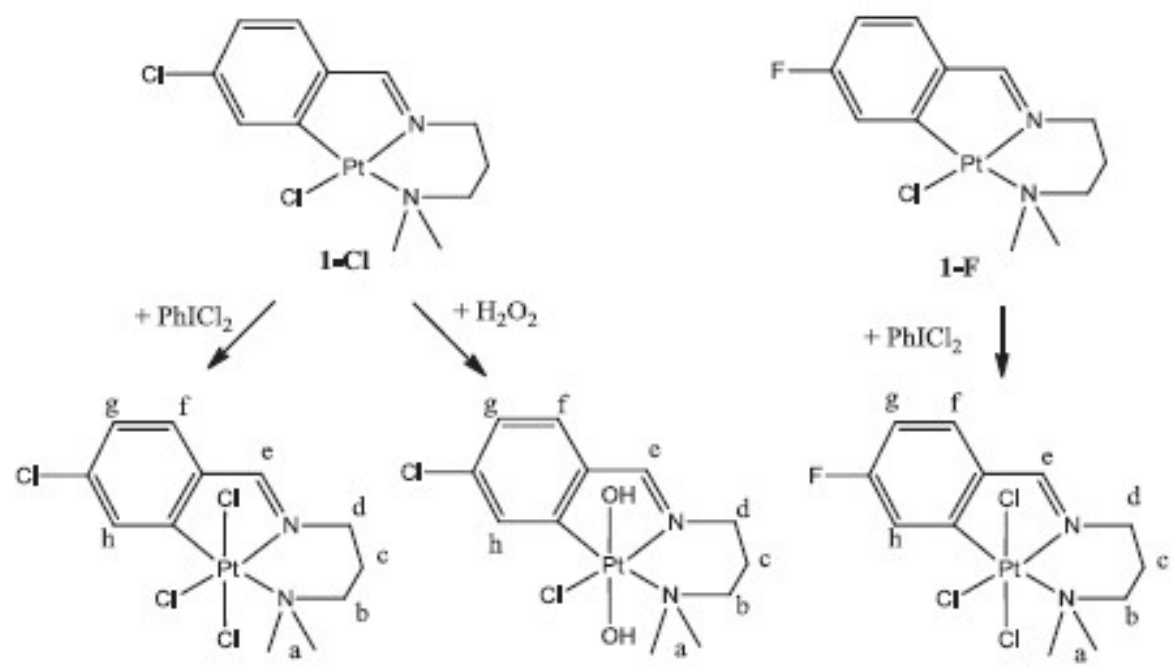

576 
FIGURE 1

578

579

580

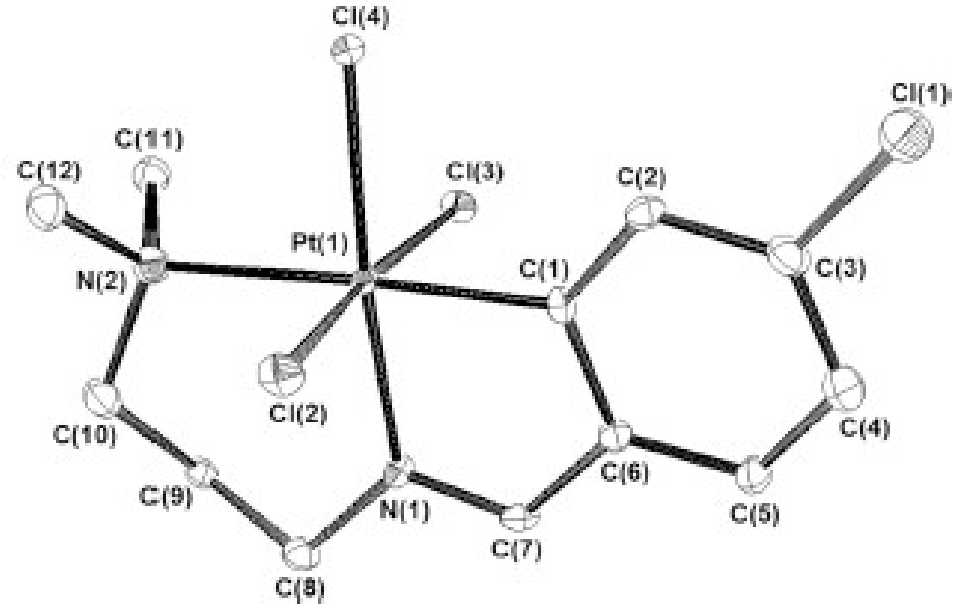

581 


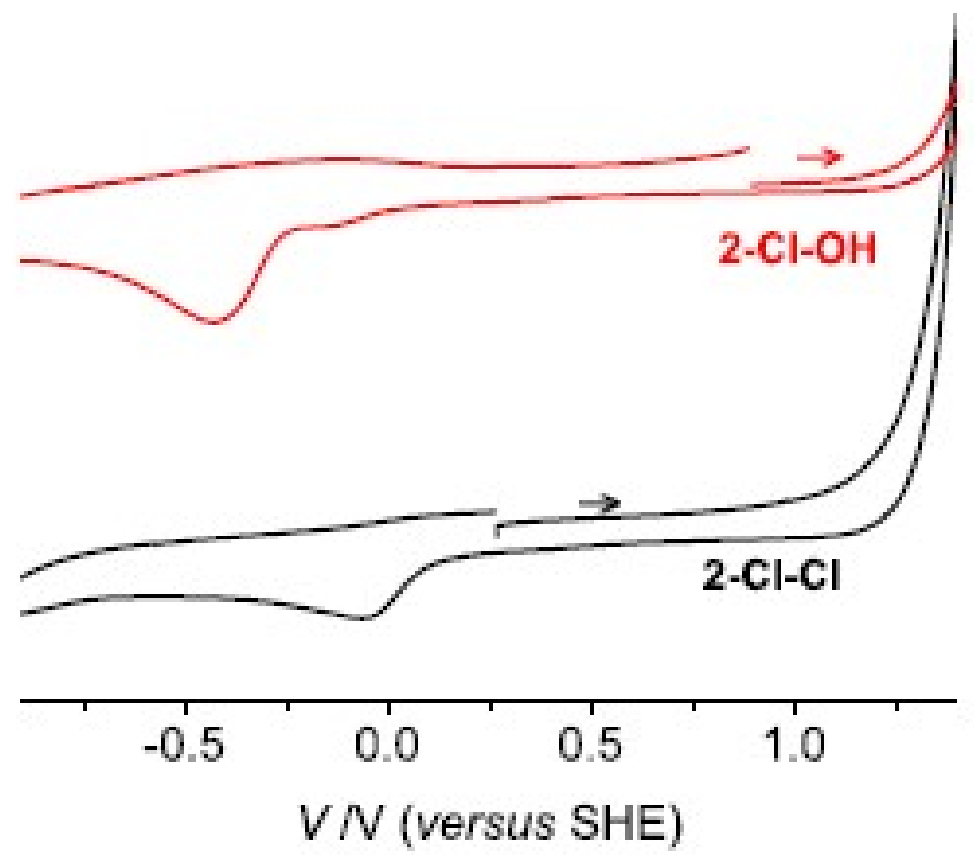


a)

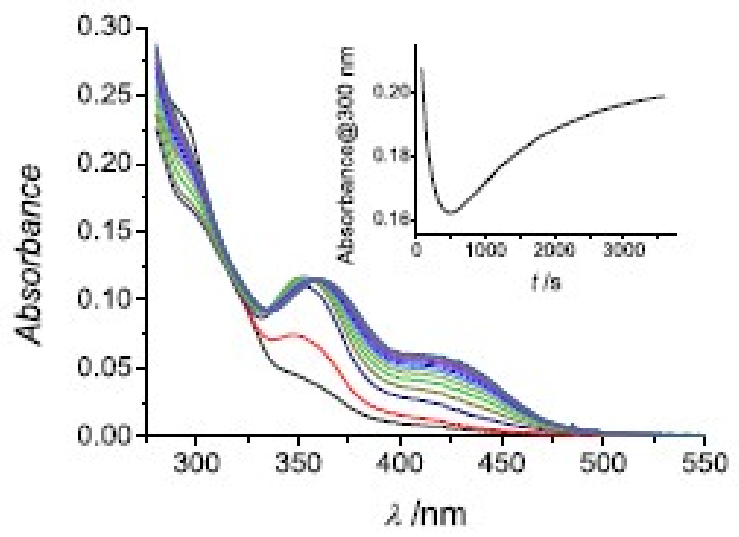

b)

- $\mathrm{pH}=8.0 ; \quad \mathrm{pH}=7.5 ; \quad \nabla \mathrm{pH}=6.5$
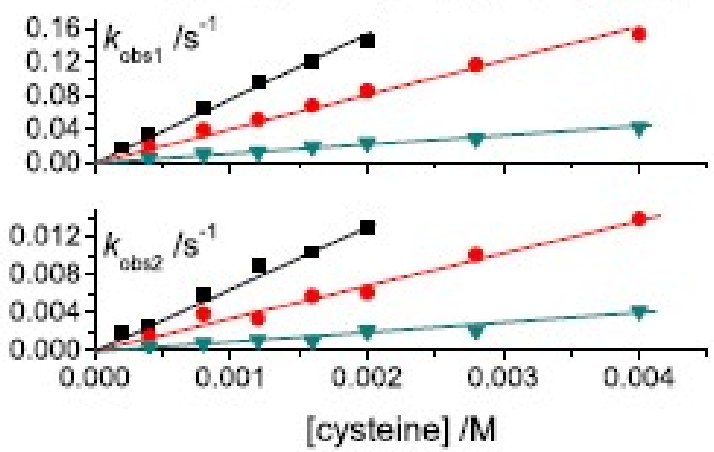
593

594

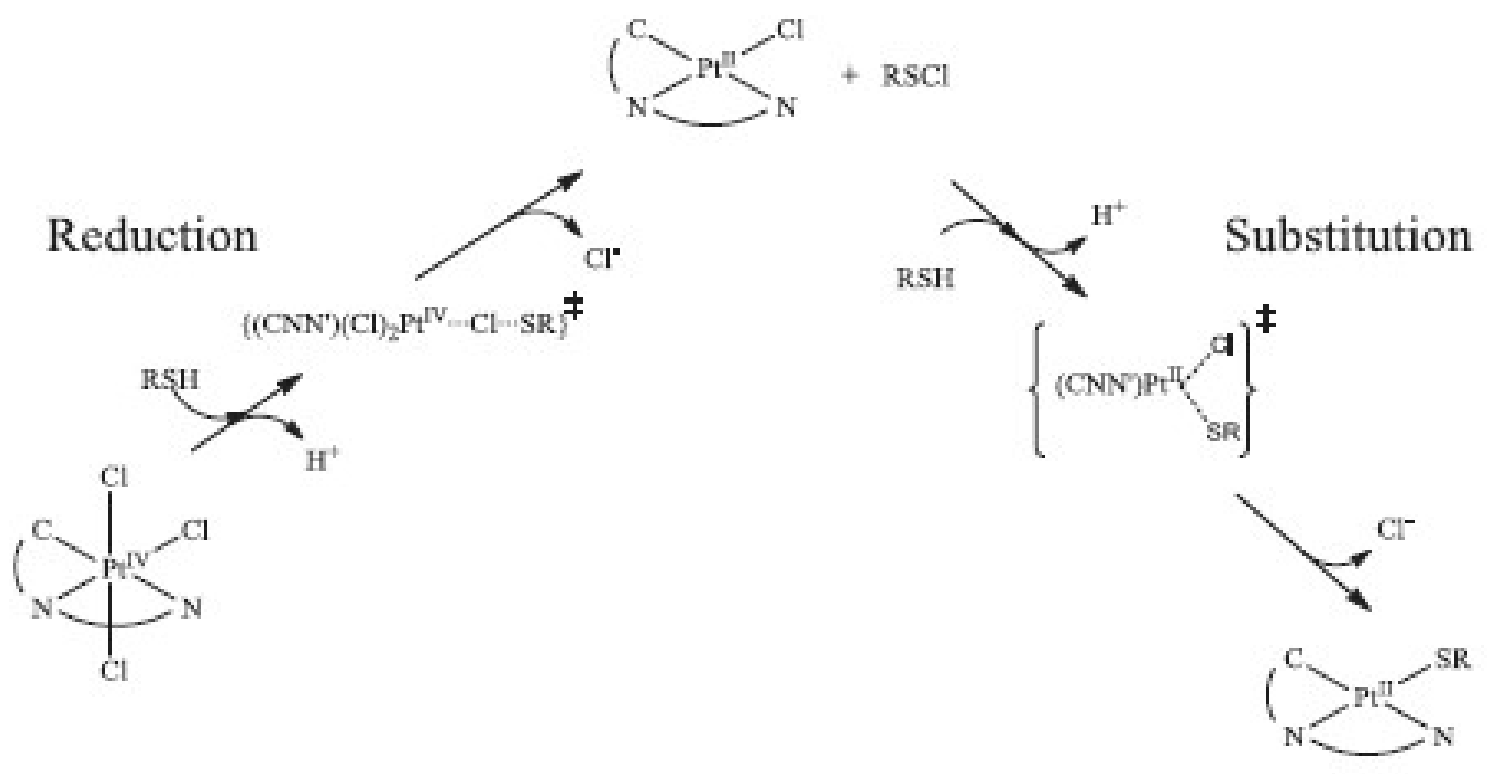

595

596 
a)

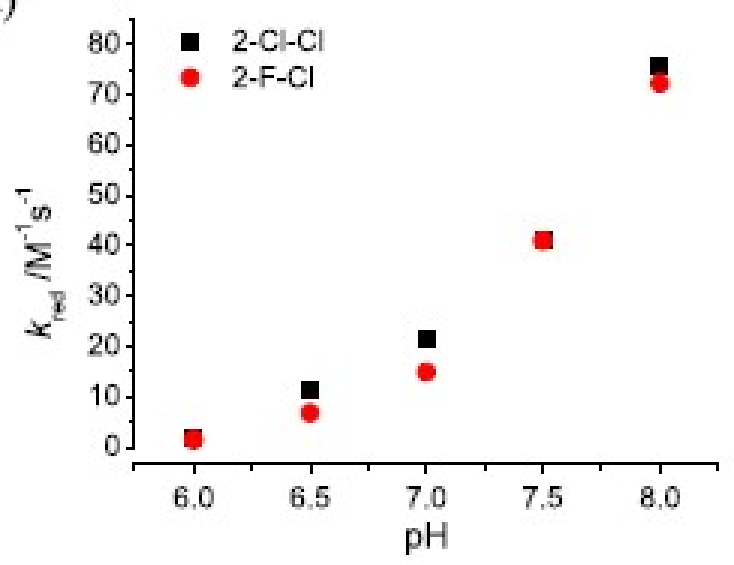

b)

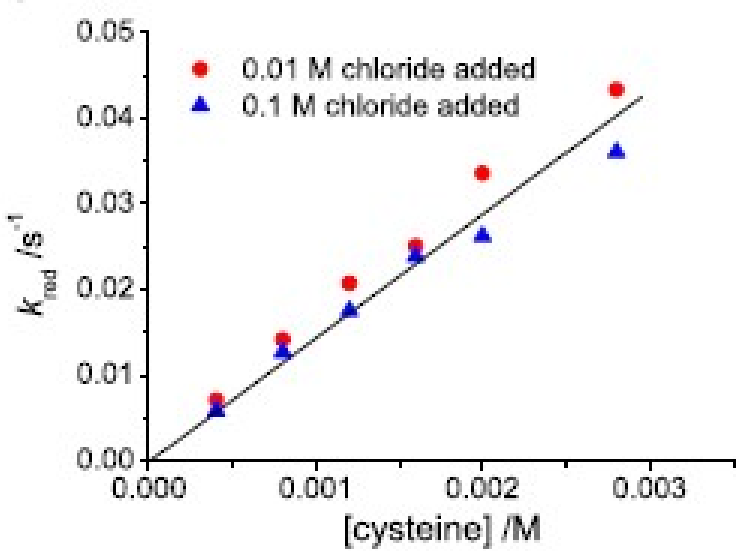


603

604

605

a)

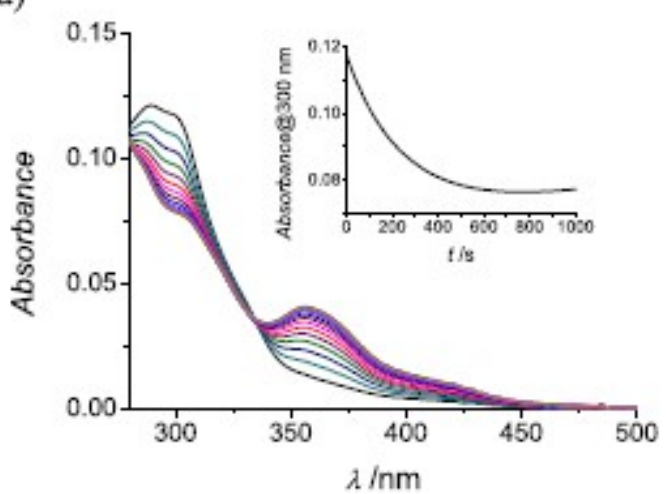

b)

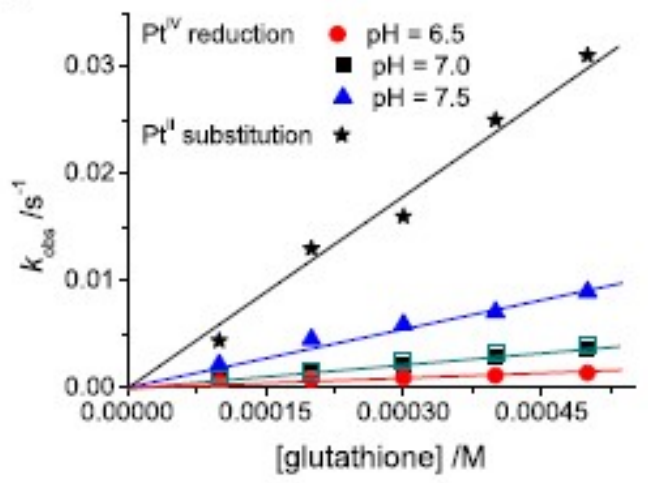

607 
609

610

a)

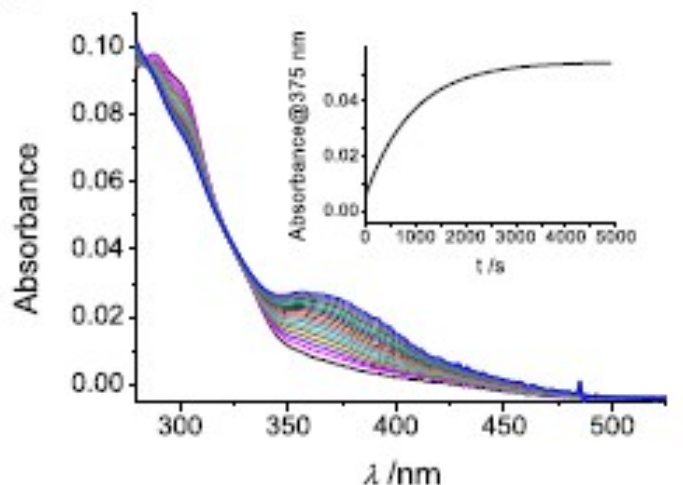

b)

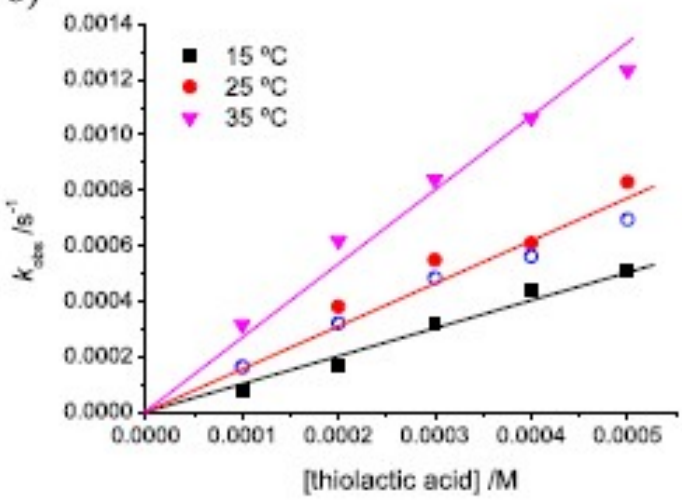


a)

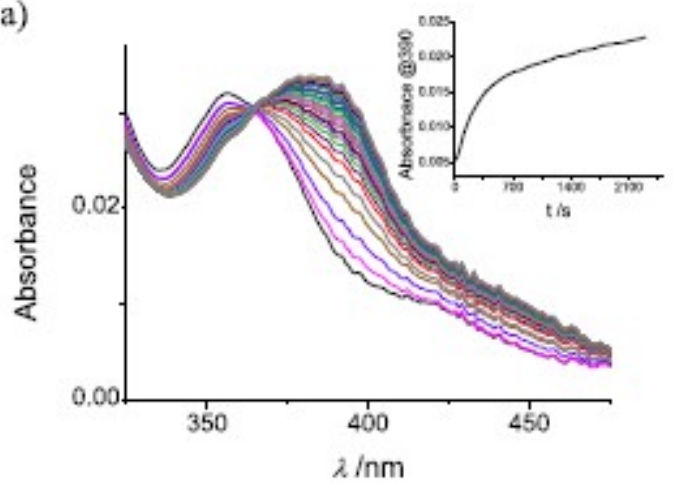

b)

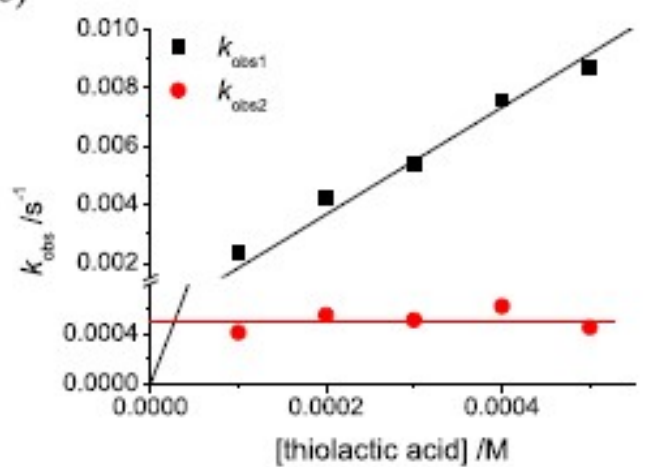


618 Table 1 Reduction potentials versus SHE for the PtIV compounds studied in this work. Relevant 619 literature data are is also included.

620

\begin{tabular}{|c|c|}
\hline Compound & $E / m V$ \\
\hline 2.Cl-Cl & -50 \\
\hline 2-P-Cl & -8 \\
\hline 2-Cl-OH & -400 \\
\hline cis,truns- $\left[\mathrm{Pt}_{t} \mathrm{Cl}_{7} \mathrm{X}_{\mathrm{Z}}(\mathrm{en})\right](\mathrm{X}=\mathrm{Cl})^{\mathrm{a}}$ & -4 \\
\hline cis,trans-[PtCl $\left.X_{2}(e n)\right](X=O H)^{x}$ & -664 \\
\hline
\end{tabular}

621

Versus SHE, from Ref. [1]. 
623 Table 2 Summary of the kinetic $(298.0 \mathrm{~K})$ and thermal and pressure activation parameters for the 624 processes occurring on complexes 2-Cl-Cl and 2-F-Cl with cysteine at $\mathrm{pH}$ 7.0.

625

\begin{tabular}{|c|c|c|c|c|c|c|c|c|}
\hline Compound & $k_{\mathrm{med}} / \mathrm{M}^{-1} \mathrm{~s}^{-1}$ & $\begin{array}{l}\text { kvur mita } \\
/ \mathrm{M}^{-1} \mathrm{~s}^{-1}\end{array}$ & $\begin{array}{l}\mathrm{AH}_{\mathrm{rad}}^{+} \\
\mathrm{hkJ} \mathrm{mol}^{-1}\end{array}$ & $\begin{array}{l}\Delta S_{\mathrm{red}}^{+} \\
/ \mathrm{J} \mathrm{K} \mathrm{K}^{-1} \mathrm{~mol}^{-1}\end{array}$ & $\begin{array}{l}\Delta V_{\mathrm{red}}^{\dagger} \\
/ \mathrm{cm}^{2} \mathrm{~mol}^{-1}\end{array}$ & $\begin{array}{l}\Delta H_{\mathrm{ver}} \mathrm{mbur}^{\dagger} \\
/ \mathrm{kJ} / \mathrm{mol}^{-1}\end{array}$ & $\begin{array}{l}\Delta S_{\text {VIm max }}{ }^{+} \\
/ \mathrm{J} \mathrm{K}^{-1} \mathrm{~mol}^{-1}\end{array}$ & $\begin{array}{l}\Delta V_{\mathrm{rnm} \mathrm{mata}}{ }^{+} \\
/ \mathrm{cm}^{2} \mathrm{~mol}^{-1}\end{array}$ \\
\hline 2-C-Cl & $21 \pm 1$ & $2.0 \pm 0.1$ & $41 \pm 3$ & $-84 \pm 11$ & $-15 \pm 2$ & $27 \pm 1$ & $-150 \pm 1$ & $-25 \pm 2$ \\
\hline 2-F-Cl & $15 \pm 1$ & $1.3 \pm 0.1$ & $44 \pm 2$ & $-77 \pm 6$ & n.d. & $44 \pm 3$ & $-97 \pm 10$ & n.d. \\
\hline
\end{tabular}

626

n.d.: Not determined. 
628 Table 3 Summary of the kinetic $(298.0 \mathrm{~K})$ and thermal and pressure activation parameters for the 629 processes occurring on complexes $2-\mathrm{Cl}-\mathrm{Cl}$ and $1-\mathrm{Cl}$ with glutathione at $\mathrm{pH}$ 7.0.

630

\begin{tabular}{|c|c|c|c|c|c|}
\hline Compound & $k_{\text {red }} / \mathrm{M}^{-1} s^{-1}$ & $\begin{array}{l}k_{\text {Fut rata }} \\
/ \mathrm{M}^{-1} s^{-1}\end{array}$ & $\begin{array}{l}\Delta H_{\mathrm{rnd}}{ }^{+} \\
/ \mathrm{kJ}^{\mathrm{mol}} \mathrm{mol}^{-1}\end{array}$ & $\begin{array}{l}\Delta S_{\mathrm{ma}^{\dagger}}^{\dagger} \\
/ \mathrm{J} \mathrm{K}^{-1} \mathrm{~mol}^{-1}\end{array}$ & $\begin{array}{l}\Delta V_{\mathrm{rad}}{ }^{\dagger} \\
/ \mathrm{cm}^{3} \mathrm{~mol}^{-1}\end{array}$ \\
\hline 2-Cl-Cl & $7.2 \pm 0.1$ & fast & $47 \pm 6$ & $-72 \pm 21$ & $-16 \pm 2$ \\
\hline $1-\mathrm{Cl}$ & - & $60 \pm 2$ & n.d. & n.d. & n.d. \\
\hline
\end{tabular}

631

n.d.: Not determined.

632 
633 Table 4 Summary of the kinetic $(298.0 \mathrm{~K})$ and thermal and pressure activation parameters for the 634 processes occurring on complexes $2 \mathrm{Cl}-\mathrm{Cl}$ and $1-\mathrm{Cl}$ with thiolactic acid at $\mathrm{pH}$ 7.0.

635

\begin{tabular}{|c|c|c|c|c|c|c|}
\hline Compound & $\begin{array}{l}k_{\mathrm{nad}} \\
/ \mathrm{M}^{-1} \mathrm{~s}^{-1}\end{array}$ & $\begin{array}{l}k_{\text {mat mas }} \\
/ \mathrm{M}^{-1} \mathrm{~s}^{-1}\end{array}$ & $\begin{array}{l}k_{\text {vnd }} \text { cthal } \\
/ s^{-1}\end{array}$ & $\begin{array}{l}\Delta H_{\mathrm{mad}^{\dagger}} \\
\mathrm{KJ} \mathrm{mol}^{-1}\end{array}$ & $\begin{array}{l}\Delta S_{\mathrm{rad}}^{\dagger} \\
/ \mathrm{J} \mathrm{K} \mathrm{K}^{-1} \mathrm{~mol}^{-1}\end{array}$ & $\begin{array}{l}\Delta V_{\mathrm{med}^{+}} \\
/ \mathrm{cm}^{2} \mathrm{~mol}^{-1}\end{array}$ \\
\hline 2-Cl-Cl & $1.7 \pm 0.1$ & fast & fast & $32 \pm 1$ & $-134 \pm 1$ & $-22 \pm 2$ \\
\hline 1-C & - & $18.0 \pm 1$ & $5 \pm 1$ & n.d. & n.d. & n.d. \\
\hline
\end{tabular}

636

n.d.: Not determined. 
638 Table 5 Summary of redox, acidity, kinetic and thermal and pressure activation data for the processes 639 occurring on the redox reaction between PtIV 2-Cl-Cl complex and the different thiol-containing 640 biomolecules utilised in this work.

641

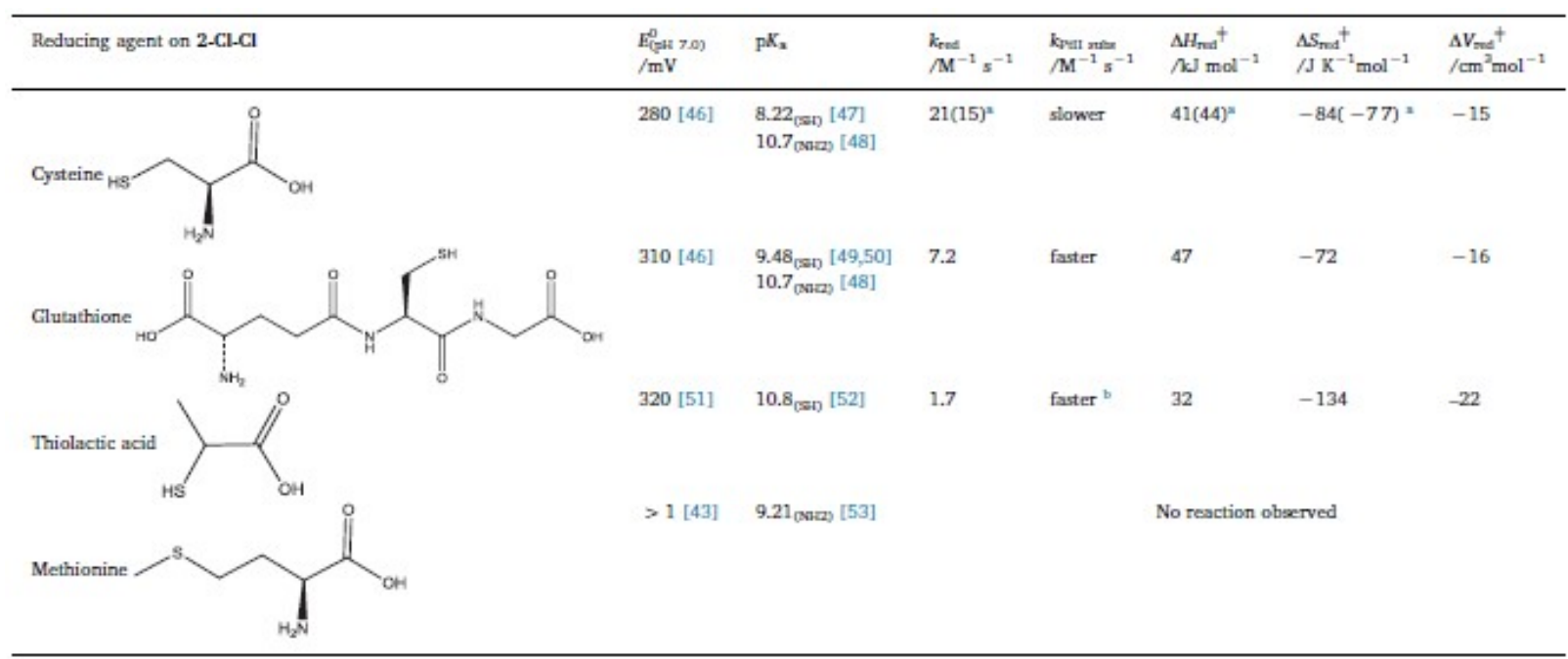

a Values in parentheses for the 2-F-Cl complex.

Chelating reaction follows. 